\title{
Introduction
}

\section{Corpus, Context and Pragmatics}

\author{
Róisín Ní Mhocháin ${ }^{1}$ (D) Anne O’Keeffe ${ }^{2}$ (1)
}

(C) Springer International Publishing AG 2017

The special issue brings together a collection of papers from ongoing work within the Inter-Varietal Applied Corpus Studies (IVACS) research network. These papers focus on pragmatic concerns in relation to a variety of languages, language varieties and contexts of use. Topics span the use of questions in written academic French and English, the pragmatic specialisation of English used in the context of migrant communication within an asylum seeker holding centre, the frequency and function of lexical bundles in English as a Foreign Language materials compared with English as a Lingua Franca, a model for enhanced genre descriptions which takes consideration of pragmatics and communicative function, as well as causality in spoken and written Czech. While this is an eclectic mix, what binds them together is a quest to use pragmatics as a lens to better understand real contexts of language use through corpora. This is at the core of the new coinage of 'corpus pragmatics' which, as Romero-Trillo (2017: 1) explains in the opening issue of this journal, is broadly about "the science that describes language use in real contexts through corpora". As it has evolved, corpus linguistics (CL) has been applied to many subfields of linguistics as well as remaining a robust sub-field in its own right. Taavitsainen and Jucker (2015: 12) note that while pragmatics embraced the 'empirical turn', and other developments in linguistics over the years, corpus linguistics came into pragmatics later that other sub-fields because, "core features of pragmatics studies, such as negotiation of meanings, speech functions, and variability of language use with momentary shifts in interpersonal relations, are

Róisín Ní Mhocháin

r.nimhochain@bathspa.ac.uk

Anne O'Keeffe

anne.okeeffe@mic.ul.ie

1 Institute for Education, Bath Spa University, Newton Park, Newton St Loe, Bath BA2 9BN, UK

2 Department of English Language and Literature, Mary Immaculate College, University of Limerick, South Circular Road, Limerick V94 VN26, Ireland 
harder to catch with corpus methodology than lexical or morpho-syntactic features" (see also Romero-Trillo 2008; Brinton 2012; Rühlemann and Aijmer 2015).

As Ädel and Reppen note, however, "some subfields are more amenable to corpus-linguistic methodology than others" (2008: 1) and within the new sub-field of 'corpus pragmatics', there is need for more consideration as to how best to use CL for pragmatics research. Rühlemann and Aijmer (2015) explain that corpus pragmatics combines the key methodologies of both fields but, as this sub-area evolves, it is important to reflect on the shape that it is taking. Papers in this issue cover a range of topics, languages and contexts and they do so from different perspectives and the insights from these papers further our growing understanding of 'corpus pragmatics'. Firstly, it is note-worthy that none of the papers focuses exclusively on English. For the most part, they explore questions in languages other than English and also in contexts of use outside of the often over-represented native English speaker context. It is important that pragmatic questions are explored in a broad range of languages and language contexts as this tests any notions or assumptions of universality. As Curry and Chambers and Čermáková et al. (this volume) show in terms of French and Czech, respectively, while there is pragmatic commonage with English, corpus explorations bring to light subtleties of use which differ across languages and across contexts within languages. It is not as simple as to say that one form or pattern differs from one language to another, it is usually the case that there is language-internal variation at play also, as these papers show.

Variation, in terms of how we describe texts, is at the core of Melissourgou and Frantzi (this volume) who argue that an enhanced understanding and description of texts would benefit learners in addressing writing tasks. Their study attempts to untangle the commonly confusing terms of 'text type', 'genre' and 'register'. Their critique investigates the range of genres involved in writing tasks and they present their model in relation to their Writing Model Answers (WriMA) corpus classification of texts. Based on this, they propose a more student-friendly 'naming' system which signals the basic requirements of the task. They argue that this can assist second language learners in developing linguistic and pragmatic knowledge, which will ultimately aid competence.

The two papers which solely focus on varieties of English in this volume look at its use in two specific contexts. Firstly, Harrington looks at the use of English for communication within a community of speakers of other languages living in an asylum seeker centre. He argues that this study is unique in the sense that the speakers are not English as a Foreign Language (EFL) students. English is not their lingua franca of choice; the speakers are 'inmates' in a 'total institution'. These are testing pragmatic conditions and his study of the key words in his corpus of recordings from the asylum centre brings to light how a very small number of words are used to great pragmatic effect in the interactions in the data. Allan (this volume) takes a look at lexical bundles and how they are used in a corpus of EFL self-study books in comparison with patterns of use in the VOICE corpus. It is salient that Allen opted to use VOICE as her baseline corpus rather than a native speaker corpus. She also shows the richness of pragmatic function within the VOICE data in comparison to the self-study materials. 
This volume brings to light many pragmatic insights through the use of corpus linguistics but in the grander scheme of things, the papers illustrate some of the textures of corpus pragmatics as a new sub-field, exploring pragmatic questions across spoken and written data, across a range of languages and varieties of languages, as well as across many contexts of use.

\section{References}

Ädel, A., \& Reppen, R. (2008). The challenges of different settings: An overview. In A. Ädel \& R. Reppen (Eds.), Corpora and discourse: The challenges of different settings (pp. 1-6). Amsterdam/ Philadelphia: John Benjamins Publishing Company.

Brinton, L. J. (2012). Historical pragmatics and corpus linguistics: Problems and strategies. Language and Computers, 76, 101-131.

Romero-Trillo, J. (Ed.). (2008). Pragmatics and corpus linguistics: A mutualistic entente. Berlin/New York: Mouton de Gruyter.

Romero-Trillo, J. (2017). Corpus pragmatics. Corpus Pragmatics, 1, 1-2.

Rühlemann, C., \& Aijmer, K. (2015). Corpus pragmatics: Laying the foundations. In K. Aijmer \& C. Rühlemann (Eds.), Corpus pragmatics: A handbook (pp. 1-26). Cambridge: Cambridge University Press.

Taavitsainen, I., \& Jucker, A. H. (2015). Twenty years of historical pragmatics: Origins, developments and changing thought styles. Journal of Historical Pragmatics, 16(1), 1-24. 